\title{
The management of coronavirus disease 2019 (COVID-19)
}

\author{
Jialin $\mathrm{Liu}^{1,2}$ (1) | Siru Liü
}

\author{
${ }^{1}$ Department of Otolaryngology, West China \\ Hospital, Sichuan University, Sichuan, China \\ ${ }^{2}$ Department of Medical Informatics, West \\ China Medical School, Sichuan, China \\ ${ }^{3}$ Department of Biomedical Informatics, \\ University of Utah, Salt Lake, Utah \\ Correspondence \\ Jialin Liu, MD, Department of Medical \\ Informatics, Department of Otolaryngology, \\ Information Center, West China Hospital, \\ Sichuan University, West China Medical \\ School, 327 Room, 8th Teaching Building, \\ No.37 Wai Nan Guo Xue Xiang \\ Street, 610041 Chengdu, Sichuan, China. \\ Email: DLJL8@163.com
}

\begin{abstract}
In December 2019, a novel coronavirus causing severe acute respiratory disease occurred in Wuhan, China. It is an emerging infectious disease with widespread and rapid infectiousness. The World Health Organization declared the coronavirus outbreak to be a public health emergency of international concern on 31 January 2020. Severe COVID-19 patients should be managed and treated in a critical care unit. Performing a chest X-ray/CT can judge the severity of the disease. The management of COVID-19 patients includes epidemiological risk and patient isolation; treatment entails general supportive care, respiratory support, symptomatic treatment, nutritional support, psychological intervention, etc. The prognosis of the patients depends upon the severity of the disease, the patient's age, the underlying diseases of the patients, and the patient's overall medical condition. The management of COVID-19 should focus on early diagnosis, immediate isolation, general and optimized supportive care, and infection prevention and control.

KEYWORDS

coronavirus, COVID-19, management
\end{abstract}

\section{1 | CORONAVIRUS DISEASE 2019}

A novel coronavirus causing severe acute respiratory disease emerged recently in Wuhan, China. The World Health Organization (WHO) has declared the coronavirus outbreak to be a public health emergency of international concern on 31 January 2020. As of 23 February 2020, 2445 patients have died and 77041 confirmed cases had been identified in China and an additional 1724 were confirmed in 29 other countries. ${ }^{1}$ On 11 February 2020, the International Committee on Taxonomy of Viruses named the new coronavirus "severe acute respiratory syndrome-related coronavirus 2," or SARS-CoV-2, while the World Health Organization named the disease coronavirus disease 2019 or COVID-19. ${ }^{2}$ The novel coronavirus belongs to the $\beta$ genus coronavirus. It has enveloped, positive-strand RNA viruses, with a diameter from 60 to $140 \mathrm{~nm}$. Current research shows it has more than $85 \%$ homology with SARSr-CoV (bat-SL-CoVZC45). ${ }^{3}$ However, many important questions remain unanswered. For example, there is no certainty about the source of the virus and outbreak, the time span of the patients discharging infective viruses, and the pathogenesis. ${ }^{3}$ This article will review the epidemiologic, risk factors, presentation, investigations, management, and discharge of this emerging infectious disease.

\section{2 | EPIDIEMOLOGIC RISK}

The guidelines set forth by the National Health Committee of the People's Republic of China suggest that patients with a severe acute respiratory infection (fever, cough, fatigue) are suspected patients of COVID-19 if they have one of the following epidemiological risk factors. ${ }^{3}$ A summary of the epidemiological risk factors is as follows:

(1) A history of travel to or residence in the city of Wuhan, China, or other cities with continuous transmission of local cases in the last 14 days before system onset.

(2) Contact with a confirmed case of COVID-19 in the 14 days before illness onset.

(3) Contact with patients with fever or respiratory symptoms from Wuhan city, China, or other cities with continuous transmission of local cases in the last 14 days before symptom onset.

(4) Clustered onsets. 


\section{3 | CLINICAL PRESENTATION AND SYNDROMES}

The incubation period of COVID-19 is 1 to 14 days, usually 3 to 7 days. ${ }^{3}$ Huang et al reported mean incubation time is about 5 days (95\% confidence interval, 4 to 7 days). ${ }^{4}$ The common symptoms of the patients infected with COVID-19 include fever (83\%-98.6\%), cough (46\%-82\%), and fatigue (11-69.6\%) early on the clinical course. ${ }^{3-7}$ Some patients may have shortness of breath (breathlessness/dyspnea), muscle ache (myalgia), arthralgia, headache, chest pain, chest discomfort, sore throat (pharyngalgia), nasal congestion (rhinobyon), rhinorrhea, throat congestion, tonsil swelling, enlargement of lymph nodes, anorexia, diarrhea, nausea, abdominal pain, vomiting, heart palpitations, hemoptysis, chill, dizziness, expectoration, and so on. ${ }^{3-10}$

The typical initial symptoms of COVID-19 are primarily fever, cough, and fatigue. However, some patients present other symptoms similar to influenza or no obvious symptom of disease onset. ${ }^{11}$ Nevertheless, these atypical initial symptoms should be paid the same attention in the diagnosis as the typical symptoms.

\section{4 | PROGNOSTIC FACTORS}

The population is generally susceptible to the COVID-19. Though risk factors for severe illness are not yet clear, a number of risk factors or chronic medical conditions show more serious conditions after infection, $3,4,6,12-14$ which include:

(1) Age more than equal to 65 years.

(2) Pregnant women.

(3) Obesity.

(4) Low immune function (people with HIV infection, people with long-term use of immunosuppressive agents, etc).

(5) Underlying chronic medical conditions (diabetes mellitus, hypertension, cardiovascular diseases, lung disease, cancer, heart failure, cerebrovascular disease, renal disease, liver disease, etc).

After the infection of COVID-19, the elderly and patients with chronic underlying diseases are at the highest risk of the condition becoming more serious. Death cases were more common in the elderly and patients with chronic underlying diseases. ${ }^{5}$ Approximately one-third to one-half of severe patients had underlying comorbidities, including diabetes, hypertension, and cardiovascular disease. ${ }^{5,6}$ In another study of patients in intensive care unit (ICU) and non-ICU, patients in ICU were older (median age 66 vs 51) and had more comorbidities ( $72 \%$ vs $37 \%)^{6}$

Not only are elderly individuals and individuals with underlying chronic medical conditions affected more severely by COVID-19, pregnant women are at a higher risk, as well. During pregnancy, women will have some immune changes, which may lead to the sensitivity and severity of infectious diseases. ${ }^{15}$ Compared with the general adult population, pregnant women are more likely to have untoward outcomes. ${ }^{16}$ During the current outbreak of COVID-19, pregnant women have a high risk of developing severe infections. ${ }^{17}$

\section{5 | INVESTIGATIONS}

\section{1 | Hematology examination}

The hematology examination includes complete blood count, electrolytes, blood gas analysis, coagulation test, liver and kidney function, C-reactive protein, erythrocyte sedimentation rate, procalcitonin, lactate dehydrogenase, creatine kinase, myocardial enzyme, myoglobin, lactate, D-dimer, inflammatory factors (interleukin(IL)-6, IL-10, TNF- $\alpha$ ), urine routine test, stool routine test, and so on. ${ }^{3}$

In these studies, it was found that most patients had normal or decreased white blood cells or lymphopenia in the early phase of the disease. Most patients displayed elevated C-reactive protein level and erythrocyte sedimentation rates, and normal procalcitonin levels. ${ }^{3,5,6}$ Severe patients were significantly laboratory abnormalities (ie, leukopenia, lymphopenia, thrombocytopenia, elevated C-reactive protein levels) as compared with nonsevere patients $(P<.05) .^{5}$

\section{2 | Laboratory testing for 2019-nCoV}

It is imperative to quickly collect and test appropriate specimens of suspected cases under the guidance of laboratory experts. As samples may require multiple tests to confirm the 2019-nCoV, sufficient clinical material is recommended when sampling. The informed consent of the patient or guardian is required during sample collection, testing, and potential future research. The specimens include respiratory specimens (nasopharyngeal and oropharyngeal swabs, bronchoalveolar lavage fluid, inner-tracheal aspirate fluid, nasopharyngeal aspirate fluid, or nasal lavage fluid, sputum, biopsy or autopsy tissue, including lungs, bronchoalveolar fluid Lavage fluid, trachea, and tracheal aspiration fluid) or blood or urine. The specimens were tested by real-time polymerase chain reaction or genetic sequencing for 2019-nCoV.

\section{3 | Radiology}

Chest images (CT/X-ray imaging) manifestation include: ${ }^{3,19-21}$

(1) Multiple, patchy, sub-segmental or segmental/lobar ground-glass opacity in unilateral/bilateral.

(2) Multiple, patchy, or large patches of consolidation in unilateral/ bilateral lungs, with a little grid-like or honeycomb-shaped interlobular septal thickening, especially in the middle and lower lobes. 
The imaging manifestations of the 2019-nCoV pneumonia are similar to viral pneumonia, but it also has its own imaging characteristics. The image of some patients changes rapidly. ${ }^{21}$ Chest $\mathrm{X}$-rays and CT images of severe patients show more significant image abnormalities than non-severe patients. ${ }^{5}$ Pulmonary consolidation could be served as a sign of deterioration. ${ }^{21}$

\section{6 | MANAGEMENT}

\section{1 | Respiratory support}

The goal of respiratory support is to enable the patient to be adequately oxygenated and ventilated. Respiratory support ensures that the respiratory status of the patient does not deteriorate. ${ }^{22}$ If the cause for respiratory distress cannot be quickly identified or corrected, the patient should be provided respiratory support and possibly mechanical ventilation before the complete respiratory collapse. ${ }^{23}$ Respiration should be monitored regularly because it is linked to outcomes of treatment. High-flow nasal oxygen or noninvasive ventilation should be used in selected patients with hypoxemic respiratory failure. ${ }^{23}$

\subsubsection{Supplemental oxygen therapy}

Patients with mild to moderate pulmonary insufficiency may only need supplemental oxygen and an ability to clear secretions on their own to achieve this goal. Many patients with hypoxemia can be well supported by supplemental oxygen. Patients should be given only the minimal support needed to maintain the required oxygen levels, as hyperoxia or excess oxygen has been considered a risk factor for poor outcomes. ${ }^{24}$

The COVID-19 patients $\left(\mathrm{SpO}_{2} \geq 93 \%\right)$ do not need supplemental oxygen, only the patients with mild respiratory failure $\left(300>\mathrm{PaO}_{2} /\right.$ $\mathrm{FiO}_{2} \geq 200 \mathrm{~mm} \mathrm{Hg}, 1 \mathrm{~mm} \mathrm{Hg}=0.133 \mathrm{kPa}$ ) were recommended supplementary oxygen. ${ }^{25}$ During the therapy process, we should monitor $\mathrm{SpO}_{2}$, respiratory frequency and other indicators of patients, and maintain $\mathrm{SpO}_{2}$ in $93 \%$ to $95 \%$. $^{26,27}$

\subsection{2 | High flow nasal cannula}

The high flow nasal cannula (HFNC) has recently come into vogue as a method of providing respiratory support and may be helpful for patients with type 2 respiratory distress related to increased work of breathing. ${ }^{22}$

HFNC is recommended for mild to moderate hypoxemic respiratory failure $\left(300>\mathrm{PaO}_{2} / \mathrm{FiO}_{2} \geq 150\right)$. If it is difficult to improve oxygenation after continuous HFNC treatment for 24 hours, noninvasive positive pressure ventilation or even invasive positive pressure ventilation is recommended. ${ }^{27,28}$

\subsection{3 | Noninvasive positive pressure ventilation}

Noninvasive positive pressure ventilation (NIPPV) is one of the most important advances in emergency and critical care of patients with respiratory failure. ${ }^{29,30}$ The COVID-19 patients with $\mathrm{PaO}_{2} / \mathrm{FiO}_{2} \geq 150$ can consider NIPPV as an alternative treatment with poor efficacy of supplemental oxygen and HFNC, or alternately used with HFNC. For the patients with $150>\mathrm{PaO}_{2} / \mathrm{FiO}_{2} \geq$ 100, NIPPV can be considered as an alternative treatment for poor efficacy of oxygen supplement and HFNC in patients with $\mathrm{PaO}_{2} / \mathrm{FiO}_{2} \geq 150$, or alternatively used with HFNC. For patients with $150>\mathrm{PaO}_{2} / \mathrm{FiO}_{2} \geq 100$, it should be applied cautiously and be prepared for endotracheal tube in all time. The patients with $\mathrm{PaO}_{2} / \mathrm{FiO}_{2}<100$ is not recommended for NIPPV. ${ }^{27}$

\subsection{4 | Invasive positive pressure ventilation}

Invasive positive pressure ventilation is an effective treatment for severe respiratory failure. Pulmonary protective ventilation marked by low tidal volume and a suitable positive end expiratory pressure (PEEP) is a conventional treatment for severe pneumonia secondary to acute respiratory distress syndrome (ARDS). ${ }^{27,31,32}$ For patients with severe ARDS (oxygenation index $<100$ and PEEP $>10 \mathrm{cmH}_{2} \mathrm{O}$ ), the recommendation is strong for prone positioning for more than 12 hours/d. ${ }^{27,31,33,34}$

\subsection{5 | Extracorporeal membrane oxygenation}

Extracorporeal membrane oxygenation (ECMO) can be used purely to support oxygenation and ventilation as well as to provide circulatory support. ECMO, also called extracorporeal life support, can provide different degrees of $\mathrm{CO}_{2}$ removal and oxygenation, enabling the reduction of mechanical support and ventilator-induced lung injury risk. ${ }^{22}$ ECMO should be considered for patients with refractory hypoxemia who are difficult to correct by protective lung ventilation. $^{35,36}$

Patients with severe COVID-19 progress more quickly. If patients still are difficult to improve the hypoxic state after standard ARDS treatment, ${ }^{31}$ ECMO should be enabled in time before multiple organ damage caused by hypoxia or the ventilator is set too high. ECMO can be recommended in the following situations ${ }^{37}$ :

(1) $\mathrm{PaO}_{2} / \mathrm{FiO}_{2}<50 \mathrm{~mm} \mathrm{Hg}>3$ hours;

(2) $\mathrm{PaO}_{2} / \mathrm{FiO}_{2}<80 \mathrm{~mm} \mathrm{Hg}>6$ hours;

(3) $\mathrm{FiO}_{2}=1.0, \mathrm{PaO}_{2} / \mathrm{FiO}_{2}<100 \mathrm{~mm} \mathrm{Hg}$;

(4) $\mathrm{pH}<7.25$, and $\mathrm{PaCO}_{2}>60 \mathrm{~mm} \mathrm{Hg}>6$ hours, and $\mathrm{R}>35$ /min;

(5) $\mathrm{R}>35 / \mathrm{min}, \mathrm{pH}<7.2$, and Pplat $>30 \mathrm{cmH}_{2} \mathrm{O}$;

(6) Severe pulmonary air leak syndromes;

(7) Cardiac arrest or cardiogenic shock. 


\section{2 | Cope with organs injuries caused by $\mathrm{S}$ ARS-CoV-2}

SARS-CoV-2 not only may lead to pneumonia, but it may also cause multiple organ and systems injuries. These organs and systems include the liver, the kidneys, cardiovascular system, neurological system, gastrointestinal system injury, immune system, coagulation system, etc. ${ }^{38-44}$ Therefore, we should pay attention to early recognition of multiorgan injuries and optimized supportive care to the protection and prevention thereof in the treatment of COVID-19. For severe patients and patients with an unsatisfactory therapeutic effect, we should pay attention to organ function and take necessary protective measures, including mechanical ventilation, symptomatic treatment, glucocorticoids, antivirals, antishock therapy, and so on. ${ }^{45}$

\section{3 | Drug treatment}

Currently, there is no evidence from a randomized controlled trial (RCT) to support specific drug treatment against the COVID-19 in suspected or confirmed cases. ${ }^{3,46}$

\subsection{1 | Antiviral treatment}

The $\alpha$-interferon atomization inhalation, chloroquine or hydroxychloroquine, lopinavir/ritonavir orally, and remdesivir, can be considered. It is not recommended to use three or more antivirals in combination. ${ }^{3,46}$ Among these drugs, the European Medicines Agency recommended on the compassionate use of remdesivir for COVID-19. ${ }^{47}$ National Institutes of Health (NIH) recommended against the use of lopinavir/ ritonavir for the treating of COVID-19, except in the context of a clinical trial. ${ }^{46}$ An RCT of 199 patients in China showed that treatment with lopinavir/ritonavir had no benefit beyond standard care. ${ }^{48}$

\subsection{2 | Antibiotic therapy}

It is important to avoid blind or inappropriate use of antibacterial, especially combinations of broad-spectrum antibacterial. ${ }^{3}$

\subsection{3 | Corticosteroid therapy}

The use of corticosteroids for severe ARDS is controversial. Methylprednisolone can be used as appropriate for patients with rapid disease progression or severe illness. ${ }^{3,49}$

\subsubsection{Other medications}

Ibuprofen can be used when the temperature is higher than $38.5^{\circ} \mathrm{C}$. $\mathrm{H}_{2}$ receptor antagonists or proton pump inhibitors can be considered in patients with risk factors for stress ulcers and gastrointestinal bleeding. Anticholinergic drugs of $M_{1}$ and $M_{3}$ receptors are recommended for patients with dyspnea, cough, wheeze, and respiratory distress syndrome. Low-molecular-weight heparin or heparin can be used in patients with high-risk of intravenous embolism without contraindications. ${ }^{49}$

Drugs approved for other indications such as loperamide, chloroquine, chlorpromazine, cyclosporin A, and mycophenolic acid have shown anti-nova coronavirus activity in vitro, but their role in the therapy of the human disease remains debatable. ${ }^{50,51}$ Although also in the absence of high-level evidence, based on previous experience of MERS-CoV-infected subjects, the use of plasma from patients in convalescence can be considered. ${ }^{3,51}$

\section{4 | Control complications and comorbidities}

The common complications of COVID-19 are ARDS, acute renal injury, sepsis, shock, thrombotic (acute pulmonary embolism, deepvein thrombosis, ischemic stroke, myocardial infarction, and systemic arterial embolism), ventilator-associated pneumonia, catheter-related bloodstream infection, pressure ulcers, stress ulcers and gastrointestinal bleeding, ICU-related weakness, rhabdomyolysis, etc. ${ }^{6,52-54}$ To proactively prevent potential complications, we need to conduct a process of (a) close monitoring clinical deterioration signs; (b) assessing risk to recognize deteriorating patient at the early stage; (c) timely and appropriate underlying disease treatment, and (d) providing general supportive care interventions timely. Depending on the patient's condition, hemodialysis, pressure boosting treatment, fluid resuscitation, ventilation, antibiotics, and other measures should be provided in a timely manner. ${ }^{45}$

In the treatment of COVID-19, we should pay full attention to treating the original comorbidities of the patients. Many elderly patients with COVID-19 have comorbidities (underlying diseases) such as hypertension, diabetes, cardio-cerebrovascular disease, kidney disease, liver disease, obesity, malignant tumors, chronic obstructive pulmonary disease, and so on. ${ }^{5-7,45,55-57}$ These comorbidities may be key prognostic determinants, so we need to monitor changes in comorbidities, accurately assess all comorbidities of the individual, monitor for drug-drug interactions, and develop individually tailored therapeutic approaches, including antihypertensive, hypoglycemic therapy and continuous renal replacement therapy, etc. ${ }^{45}$ Patients with COVID-19 who are prescribed statin therapy for the treatment or prevention of cardiovascular disease should continue these medications. ${ }^{58}$ Renin-angiotensin-aldosterone system inhibitors should be continued in patients in otherwise stable condition who are at risk for, being evaluated for, or who are already diagnosed with COVID-19. ${ }^{59}$ However, there is no evidence that patients with COVID-19 should discontinue or continue sodium-dependent glucose transporter 2 (SGLT-2i). ${ }^{60,61}$ 


\section{5 | Traditional Chinese medicine}

In the process of treating for COVID-19, the treatments are individualized according to traditional Chinese medicine syndrome diagnosis and treatment (Bian Zheng Lun Zhi). Syndrome differentiation individually is used to guide the selection of traditional Chinese medicine treatment using traditional Chinese medicine herbal formulae. ${ }^{62}$ Some drugs and herbal formulae also were recommended for treating COVID-19 in the latest version of China guideline for diagnosis and treatment of COVID-19. ${ }^{3}$ However, the therapeutic effect of traditional Chinese medicine warrants further investigation in future studies.

\section{6 | Nutrition support}

Severe COVID-19 patients should be screened and evaluated for the risk of malnutrition based on the Subjective Global Assessment or the Nutrition Risk Screening 2002 (NRS2002) score. ${ }^{49,63}$ Clinicians must carefully observe patients' response to treatment and adjust nutrition support. In most cases, nutrition support includes food, oral supplements, tube feeding, and parenteral nutrition. It is often used interchangeably on the same patient. ${ }^{64}$ For the patients who can oral intake, a diet rich in protein, carbohydrates, and vitamins is recommended. Patients who cannot oral intake but are compatible with enteral nutrition should be given enteral nutrition as soon as possible. For the patients incompatible with enteral nutrition, parenteral nutrition should be given in time to meet the energy needs. ${ }^{49}$

\section{7 | Mental health interventions}

Because COVID-19 is an emerging infectious disease, patients with COVID-19 are often accompanied by anxiety and fear. ${ }^{3}$ These patients need appropriate mental health intervention. The menta health interventions include formal psychotherapy for psychiatric disorders and a series of wellness and resilience-based psychosocial interventions for emotional distress and social problems. ${ }^{6,66}$ The common interventions in mental health include psychological first aid, crisis counseling, psychoeducation, family outreach, social support, psychological debriefing (eg, critical event stress debriefing), and techniques for anxiety reduction. ${ }^{66-71}$ During mental health intervention, clinicians should assess and monitor risk and protective factors across all phases of an emergency and disaster. ${ }^{72}$

\section{8 | Discharge}

All patients with COVID-19 need to meet all of the following conditions to be discharged. The body temperature had returned to normal for more than 3 days; the respiratory symptoms had improved significantly; the pulmonary inflammation showed obvious signs of absorption; the nucleic acid test of the respiratory samples was negative for two consecutive times (at least one-day sampling interval); the discharged patients need to be quarantined at home for 14 days. $^{3}$ If their condition deteriorates, all discharged patients should be instructed to return to the hospital. ${ }^{53}$

\section{7 | CONCLUSION}

Quick identification of persons at risk for COVID-19 and management of COVID-19 patients is critical to slowing the spread of COVID-19 around the world. Clinical care of patients with suspected COVID-19 should focus on early identification, immediate isolation (separation), implementation of appropriate infection prevention and control (IPC) measures and provision optimized supportive care. ${ }^{73}$ COVID-19 is an emerging infectious disease, and continuous efforts are needed to explore effective treatments for this emerging acute respiratory infection. ${ }^{9}$

\section{CONFLICT OF INTERESTS}

The authors declare that there are no conflict of interests.

\section{AUTHOR CONTRIBUTIONS}

$J \mathrm{~L}$ and $\mathrm{SL}$ conceived the study. $\mathrm{J}$ and $\mathrm{SL}$ performed the collection and analysis of literature and data, and drafted the manuscript. All authors reviewed and approved the final version.

\section{ORCID}

Jialin Liu (D) http://orcid.org/0000-0002-1369-4625

\section{REFERENCES}

1. https://voice.baidu.com/act/newpneumonia/newpneumonia. Accessed on February 23, 2020.

2. https://cmajnews.com/2020/02/14/coronavirus-1095847/. Accessed on February 18, 2020.

3. General Office of National Health Committee (China). Guideline for the diagnosis and treatment of novel coronavirus (2019-nCoV) infected pneumonia (Trial Version 6). 2020. Accessed on February 20, 2020.

4. Li Q, Guan X, Wu P, et al. Early transmission dynamics in Wuhan, China, of novel coronavirus-infected pneumonia. N Engl J Med. 2020; 382:1199-1207. https://doi.org/10.1056/NEJMoa2001316

5. Huang C, Wang Y, Li X, et al. Clinical features of patients infected with 2019 novel coronavirus in Wuhan, China. Lancet. 2020;395(10223): 497-506.

6. Wang D, Hu B, Hu C, et al. Clinical characteristics of 138 hospitalized patients with 2019 novel coronavirus-infected pneumonia in Wuhan. JAMA. 2020;323:1061. https://doi.org/10.1001/jama.2020.1585

7. Chen N, Zhou M, Dong X, et al. Epidemiological and clinical characteristics of 99 cases of 2019 novel coronavirus pneumonia in Wuhan, China: a descriptive study. Lancet. 2020;395(10223):507-513.

8. https://www.cdc.gov/coronavirus/2019-ncov/hcp/clinical-guidancemanagement-patients.html. Accessed on February 25, 2020.

9. Weijie G, Zhengyi N, Yu H, et al. Clinical characteristics of 2019 novel coronavirus infection in China. medRxiv preprint. https://doi.org/10 1101/2020.02.06.20020974

10. Liu K, Fang YY, Deng Y, et al. Clinical characteristics of nove coronavirus cases in tertiary hospitals in Hubei province. Chin Med J (Engl). 2020;133:1025-1031. https://doi.org/10.1097/ CM9.0000000000000744 
11. Chan JFW, Yuan S, Kok KH, et al. A familial cluster of pneumonia associated with the 2019 novel person transmission: a study of family cluster. Lancet. 2020;395(10223):514-523.

12. Liao $\mathrm{X}$, Wang $\mathrm{B}$, Kang $\mathrm{Y}$. Novel coronavirus infection during the 2019-2020 epidemic: preparing intensive care Units-the experience in Sichuan Province, China. Intensive Care Med. 2020;46:357-360. https://doi.org/10.1007/s00134-020-05954-2

13. Martinez L, Cheng W, Wang $X$, et al. A risk classification model to predict mortality among laboratory-confirmed avian influenza $A$ H7N9 patients: a population-based observational cohort study. $J$ Infect Dis. 2019;220(11):1780-1789.

14. Redfern OC, Smith GB, Prytherch DR, Meredith P, Inada-Kim M, Schmidt PE. A comparison of the quick sequential (sepsis-related) organ failure assessment score and the national early warning score in non-ICU patients with/without infection. Crit Care Med. 2018; 46(12):1923-1933.

15. Jamieson DJ, Theiler RN, Rasmussen SA. Emerging infections and pregnancy. Emerg Infect Dis. 2006;12(11):1638-1643.

16. Beigi RH. Emerging infectious diseases in pregnancy. Obstet Gynecol. 2017;129(5):896-906.

17. Schwartz DA, Graham AL. Potential maternal and infant outcomes from (Wuhan) coronavirus 2019-nCoV infecting pregnant women: lessons from SARS, MERS, and other human coronavirus infections. Viruses. 2020;12(2):194. https://doi.org/10.3390/v12020194

18. WHO. Laboratory testing for 2019 novel coronavirus (2019-nCoV) in suspected human cases. https://www.who.int/publications-detail/ laboratory-testing-for-2019-novel-coronavirus-in-suspected-humancases-20200117. Accessed on March 25, 2020.

19. Chung M, Bernheim A, Mei X, et al. CT imaging features of 2019 novel coronavirus. Radiology. 2020;295. https://doi.org/10.1148/radiol. 2020200230

20. Pan Y, Guan H, Zhou S, et al. Initial CT findings and temporal changes in patients with the novel coronavirus pneumonia (2019-nCoV): a study of 63 patients in Wuhan, China. Eur Radiol. 2020;1-4. https:// doi.org/10.1007/s00330-020-06731-x

21. Song F, Shi N, Shan F, et al. Emerging coronavirus 2019-nCoV pneumonia. Radiology. 2020;295:210-217. https://doi.org/10.1148/ radiol.2020200274

22. Jennifer AL, ed. Adult Critical Care Medicine: A Clinical Casebook. Cham, Switzerland: Springer; 2019.

23. Salim A, Brown C, Inaba K, et al. Surgical Critical Care Therapy: a Clinically Oriented Practical Approach. Cham, Switzerland: Springer; 2018.

24. Page D, Ablordeppey E, Wessman BT, et al. Emergency department hyperoxia is associated with increased mortality in mechanically ventilated patients: a cohort study. Crit Care. 2018;22(1):9. https://doi. org/10.1186/s13054-017-1926-4

25. Siemieniuk RAC, Chu DK, Kim LHY, et al. Oxygen therapy for acutely ill medical patients: a clinical practice guideline. BMJ. 2018;363: k4169. https://doi.org/10.1136/bmj.k4169

26. O'Driscoll BR, Howard LS, Earis J, Mak V. BTS guideline for oxygen use in adults in healthcare and emergency settings. Thorax. 2017; 72(Suppl 1):ii1-ii90.

27. Yuan X, Mu JS, Mo GX, Hu XS, Yan P, Xie LX. Respiratory support for severe 2019-nCoV pneumonia suffering from acute respiratory failure: time and strategy. Zhonghua Jie He He Hu Xi Za Zhi. 2020;43(3): E010. https://doi.org/10.3760/cma.j.issn.1001-0939.2020.0010

28. Respiratory \& Critical Care Medicine Group of Chinese Thoracic Society, Respiratory \& Critical Care Medicine Committee of Chinese Association of Chest Physician. Expert consensus of high-flow nasal cannula oxygen therapy on clinical application regularity. Zhonghua Jie He He Hu Xi Za Zhi. 2019;42(2):83-91.

29. Cabrini L, Landoni G, Oriani A, et al. Noninvasive ventilation and survival in acute care settings: a comprehensive systematic review and meta-analysis of randomized controlled trials. Crit Care Med. 2015;43:880-888.

30. Archambault PM, t-Onge M. Invasive and noninvasive ventilation in the emergency department. Emerg Med Clin North Am. 2012;30(2): 421-449.

31. Fan E, Del Sorbo L, Goligher EC, et al. An Official American Thoracic Society/European Society of Intensive Care Medicine/Society of Critical Care Medicine Clinical Practice Guideline: mechanical ventilation in adult patients with acute respiratory distress syndrome. Am J Respir Crit Care Med. 2017;195(9):1253-1263.

32. Respiratory \& Critical Care Medicine Group of Chinese Thoracic Society. Mechanical ventilation guidelines for patients with acute respiratory distress syndrome (trail). Zhonghua Yi Xue Za Zhi. 2016; 96(6):404-424.

33. Munshi L, Del Sorbo L, Adhikari NKJ, et al. Prone position for acute respiratory distress syndrome. A systematic review and metaanalysis. Ann Am Thorac Soc. 2017;14(S4):S280-S288.

34. Heines SJH, Strauch U, van de Poll MCG, Roekaerts PMHJ, Bergmans DCJJ. Clinical implementation of electric impedance tomography in the treatment of ARDS: a single centre experience. J Clin Monit Comput. 2019;33(2):291-300.

35. ELSO. Respiratory Support Guidelines. [EB/OL]. 2017. https:// www.elso.org/Resources/Guidelines.aspx. Accessed on February 18, 2020.

36. Combes A, Hajage D, Capellier G, et al. Extracorporeal membrane oxygenation for severe acute respiratory distress syndrome. N Engl J Med. 2018;378(21):1965-1975.

37. Chinese Society of Extracorporeal Life Support. Recommendations on extracorporeal life support for critically ill patients with novel coronavirus pneumonia. Zhonghua Jie He He Hu Xi Za Zhi. 2020;43(00):009. https://doi.org/10.3760/cma.j.issn.1001-0939. 2020.0009

38. Cheng H, Wang Y, Wang GQ. Organ-protective effect of angiotensinconverting enzyme 2 and its effect on the prognosis of COVID-19. J Med Virol. 2020. https://doi.org/10.1002/jmv.25785

39. Xiao F, Tang M, Zheng X, Liu Y, Li X, Shan H. Evidence for gastrointestinal infection of SARS-CoV-2. Gastroenterology. 2020;158: 1831.e3-1833.e3.

40. Han H, Yang L, Liu R. Prominent changes in blood coagulation of patients with SARS-CoV-2 infection. Clin Chem Lab Med. 2020;0, https://doi.org/10.1515/cclm-2020-0188

41. Zhang C, Shi L, Wang FS. Liver injury in COVID-19: management and challenges. Lancet Gastroenterol Hepatol. 2020;5:428-430.

42. Baig AM. Neurological manifestations in COVID-19 caused by SARSCoV-2. CNS Neurosci Ther. 2020;26(5):499-501.

43. Madjid M, Safavi-Naeini P, Solomon SD, Vardeny O. Potential effects of coronaviruses on the cardiovascular system: a review. JAMA Cardiol. 2020. https://doi.org/10.1001/jamacardio.2020.1286

44. Lin L, Cao W, Li T. Hypothesis for potential pathogenesis of SARSCoV-2 infection-a review of immune changes in patients with viral pneumonia. Emerg Microbes Infect. 2020;9(1):727-732.

45. Wang T, Du Z, Zhu F, et al. Comorbidities and multi-organ injuries in the treatment of COVID-19. Lancet. 2020;395(10228):e52. https:// doi.org/10.1016/S0140-6736(20)30558-4

46. NIH. COVID-19 treatment guideline. https://www.covid19treatment guidelines.nih.gov/therapeutic-options-under-investigation/. Accessed on April 25, 2020

47. European medicines agency. EMA provides recommendations on compassionate use of remdesivir for COVID-19. European medicines agency science medicines health, 3 April 2020, EMA/ $152575 / 2020$

48. Cao B, Wang Y, Wen D, et al. A trial of lopinavir-ritonavir in adults hospitalized with severe COVID-19. N Engl J Med. 2020;382(19): 1787-1799. https://doi.org/10.1056/NEJMoa2001282 
49. Jin $\mathrm{YH}$, Cai L, Cheng $\mathrm{ZS}$, et al. A rapid advice guideline for the diagnosis and treatment of 2019 novel coronavirus (2019-nCoV) infected pneumonia (standard version). Mil Med Res. 2020;7(1):4. https://doi. org/10.1186/s40779-020-0233-6

50. de Wit E, van Doremalen N, Falzarano D, Munster VJ. SARS and MERS: recent insights into emerging coronaviruses. Nat Rev Microbiol. 2016;14(8):523-534.

51. Mo Y, Fisher D. A review of treatment modalities for Middle East Respiratory Syndrome. J Antimicrob Chemother. 2016;71(12): 3340-3350.

52. Klok FA, Kruip MJHA, van der Meer NJM, et al. Incidence of thrombotic complications in critically ill ICU patients with COVID-19. Thromb Res. 2020;S0049-3848(20):30120-30121. https://doi.org/10. 1016/j.thromres.2020.04.013

53. World Health Organization. Clinical management of severe acute respiratory infection (SARI) when COVID-19 disease is suspected (Interim guidance). March 13, 2020.

54. Guan W, Ni Z, Hu Y, et al. Clinical characteristics of 2019 novel coronavirus infection in China. N Engl J Med. 2020;382:1708-1720. https://doi.org/10.1056/NEJMoa2002032

55. Government of Canada. Clinical management of patients with moderate to severe COVID-19 - Interim guidance. April 2, 2000.

56. Richardson S, Hirsch JS, Narasimhan M, et al. Presenting characteristics, comorbidities, and outcomes among 5700 patients hospitalized with COVID-19 in the New York city area. JAMA. 2020;e206775. https://doi.org/10.1001/jama.2020.6775

57. Wu Z, McGoogan JM. Characteristics of and important lessons from the coronavirus disease 2019 (COVID-19) outbreak in China: summary of a report of 72314 cases from the Chinese Center for Disease Control and Prevention. JAMA. 2020;323:1239. https://doi.org/10. 1001/jama.2020.2648

58. NIH. COVID-19 treatment guideline. https://www.covid19treatment guidelines.nih.gov/concomitant-medications/. Accessed on April $25,2020$.

59. Vaduganathan M, Vardeny O, Michel T, McMurray JJV, Pfeffer MA, Solomon SD. Renin-angiotensin-aldosterone system inhibitors in patients with Covid-19. N Engl J Med. 2020;382(17):1653-1659.

60. Pal R, Bhadada SK. Should anti-diabetic medications be reconsidered amid COVID-19 pandemic? Diabetes Res Clin Pract. 2020;163:108146.

61. Ceriello A, Stoian AP, Rizzo M. COVID-19 and diabetes management: what should be considered? Diabetes Res Clin Pract. 2020;163:108151.

62. Jiang L, Liu B, Xie Q, et al. Investigation into the influence of physician for treatment based on syndrome differentiation. Evid Based
Complement Alternat Med. 2013;2013:587234-16. https://doi.org/10. $1155 / 2013 / 587234$

63. Gultekin A, Memis D, Turan Inal M, et al. The impact of nutritional risk screening 2002 and subjective global assessment upon prognosis for intensive care patients. Progr Nutr. 2016;18(1):47-55.

64. Kondrup J, Allison SP, Elia M, Vellas B, Plauth M. Educational and Clinical Practice Committee, European Society of parenteral and enteral nutrition. ESPEN Guideline Nutr Screen. 2003;22(4): 415-421. 2002

65. North CS, Pfefferbaum B. Mental health response to community disasters: a systematic review. JAMA. 2013;310(5):507-518.

66. Norwood AE, Ursano RJ, Fullerton CS. Disaster psychiatry: principles and practice. Psychiatr Q. 2000;71(3):207-226.

67. Pfefferbaum B, Shaw JA. American Academy of Child and Adolescent Psychiatry (AACAP) Committee on Quality Issues (CQI). Practice parameter on disaster preparedness. J Am Acad Child Adolesc Psychiatr. 2013;52(11):1224-1238.

68. North CS, King RV, Fowler RL, et al. Psychiatric disorders among transported hurricane evacuees: acute-phase findings in a large receiving shelter site. Psychiatr Ann. 2008;38(2):104-113.

69. Roberts NP, Kitchiner NJ, Kenardy J, Bisson JI. Systematic review and meta-analysis of multiple-session early interventions following traumatic events. Am J Psychiatry. 2009;166(3):293-301.

70. Rose S, Bisson J, Churchill R, Wessely S. Psychological debriefing for preventing post traumatic stress disorder (PTSD). Cochrane Database Syst Rev. 2002;(2):CD000560.

71. Reyes G, Elhai JD. Psychosocial interventions in the early phases of disasters. Psychother Theory Res Prac Train. 2004;41(4):399-411.

72. Généreux M, Schluter PJ, Takahashi S, et al. Psychosocial management before, during, and after emergencies and disasters-results from the Kobe Expert Meeting. Int J Environ Res Public Health. 2019;16(8): E1309.

73. Alavi-Moghaddam M. A novel coronavirus outbreak from Wuhan city in China, rapid need for emergency departments preparedness and response; a letter to editor. Arch Acad Emerg Med. 2020;8(1):e12.

How to cite this article: Liu J, Liu S. The management of coronavirus disease 2019 (COVID-19). J Med Virol. 2020;92: 1484-1490. https://doi.org/10.1002/jmv.25965 